livraisons

d'Histoire

de l'Architecture

\section{Livraisons de l'histoire de l'architecture}

$19 \mid 2010$

Du remploi à l'éphémère

\title{
La destruction des églises de Meurthe-et-Moselle en 1914-1918
}

Churches' destruction in Meurthe-et-Moselle, during 1914-1918

Kirchenzerstörungen im Département Meurthe-et-Moselle, zwischen 1914 und 1918

\section{Nicolas Padiou}

\section{OpenEdition}

\section{Journals}

Édition électronique

URL : http://journals.openedition.org/lha/240

DOI : $10.4000 /$ /ha. 240

ISSN : 1960-5994

\section{Éditeur}

Association Livraisons d'histoire de l'architecture - LHA

\section{Édition imprimée}

Date de publication : 10 juin 2010

Pagination : 77-96

ISSN : 1627-4970

\section{Référence électronique}

Nicolas Padiou, «La destruction des églises de Meurthe-et-Moselle en 1914-1918 », Livraisons de

l'histoire de l'architecture [En ligne], 19 | 2010, mis en ligne le 10 juin 2010, consulté le 19 avril 2019

URL : http://journals.openedition.org//ha/240 ; DOI : 10.4000//ha.240

Ce document a été généré automatiquement le 19 avril 2019.

Tous droits réservés à l'Association LHA 


\section{La destruction des églises de Meurthe- et-Moselle en 1914-1918}

Churches' destruction in Meurthe-et-Moselle, during 1914-1918

Kirchenzerstörungen im Département Meurthe-et-Moselle, zwischen 1914 und 1918

Nicolas Padiou

1 Une dizaine de départements du nord-est de la France ont été reconstruits à l'issue de la Première Guerre mondiale. Cette première reconstruction est longtemps restée dans l'ombre de la deuxième. Depuis le début des années 1990, elle a cependant fait l'objet de nombreuses publications et commence à être bien connue ${ }^{1}$. On dispose notamment de solides monographies sur les églises reconstruites en Picardie ou dans le Pas-de-Calais ${ }^{2}$.

2 La reconstruction des églises a suscité beaucoup d'intérêt, mais leur destruction reste encore mal connue. Les historiens de la Première Guerre mondiale ont surtout abordé les églises en temps de guerre du point de vue de l'anthropologie historique ${ }^{3}$. Les spécialistes du patrimoine se sont essentiellement concentrés, pour leur part, sur quelques édifices célèbres comme la cathédrale de Reims ${ }^{4}$.

Certains historiens français considèrent que les armées allemandes ont délibérément détruit les églises françaises ${ }^{5}$. Quant aux historiens allemands, ils ne nient pas les faits imputés à l'armée de leur. pays, mais ils s'intéressent plus à la représentation des destructions qu'à leur réalité concrète ${ }^{6}$. Or, pour bien comprendre le rôle joué par les églises en 1914-1918 et lors de la reconstruction, il faut non seulement étudier leur place dans la propagande de guerre, mais aussi s'efforcer de mesurer l'ampleur matérielle des destructions. C'est ce qu'on se propose de montrer au sujet des églises du département de Meurthe-et-Moselle, églises dont la destruction et la reconstruction n'ont fait l'objet d'aucune étude récente, malgré l'existence d'un important fonds des dommages de guerre dans les archives du département ${ }^{7}$. 


\section{Les églises en Meurthe-et-Moselle aux alentours de 1900}

4 En 1900, la Meurthe-et-Moselle est encore un département neuf. Comme le territoire de Belfort, elle est née de la défaite française lors de la guerre contre l'Allemagne en 1870-1871. L'empire allemand a annexé le Bas-Rhin, la plus grande partie du Haut-Rhin et de la Moselle, ainsi que deux arrondissements de la Meurthe et quelques communes des Vosges. L'arrondissement de Briey appartenant jusqu'alors à la Moselle a été rattaché à ce qui subsistait de la Meurthe pour constituer la Meurthe-et-Moselle. Le nouveau département, dont la préfecture demeurait à Nancy, disposait dès lors d'une courte frontière avec la Belgique et avec le Luxembourg ainsi que d'une très longue frontière avec l'ancienne Moselle et le Bas-Rhin, désormais rattachés à l'Allemagne ${ }^{8}$.

5 La découverte d'immenses gisements de minerai de fer dans les environs de Nancy, de Pont-à-Mousson et surtout dans le Pays haut entre Briey et Longwy, suscita un très grand essor industriel ${ }^{9}$. La population du département augmenta de $40 \%$ pendant les quarante ans qui suivirent la défaite de 1871 . De modestes villages se transformèrent rapidement en centres industriels de premier plan. Nancy s'imposa comme la capitale incontestée de l'est de la France en accueillant une grande partie des administrations autrefois installées à Strasbourg et à Metz et en rayonnant dans le domaine des arts décoratifs par le biais de l'école de Nancy. D'autres villes comme Lunéville, Pont-à-Mousson, Toul et Longwy connurent elles aussi un essor rapide. Mais, le département demeurait essentiellement rural. Au début du XXe siècle, il comptait plus de 600 communes pour une population d'environ 500.000 habitants.

6 Les villages traditionnels lorrains avaient souvent été reconstruits après la Guerre de Trente ans ${ }^{10}$. Ils se présentaient soit sous la forme de tas très denses, soit, le plus souvent, sous la forme de village-rue, les maisons aux façades continues s'étirant dans ce dernier cas de part et d'autre d'une voie unique, parfois large de plusieurs dizaines de mètres mais facile à défendre en ses deux extrémités. L'habitat isolé était très rare : à quelques exceptions près, chaque agglomération constituait une commune. Une telle situation facilitait la correspondance entre paroisse et commune, qui constituait l'idéal de la France concordataire du milieu du XIX ${ }^{\mathrm{e}}$ siècle ${ }^{11}$. La coïncidence des cadres communaux et paroissiaux s'imposait d'autant plus facilement que la Lorraine avait constitué un des "bastions de la Contre-réforme » et demeurait très catholique au début du XX $\mathrm{XX}^{\mathrm{e}}$ siècle $^{12}$.

7 Certaines des nombreuses églises détruites pendant la Guerre de Trente ans étaient à peine reconstruites quand le duché de Lorraine fut définitivement rattaché au royaume de France, en $1766^{13}$. Après les troubles révolutionnaires, de nombreuses églises se trouvaient par ailleurs dans un état déplorable ${ }^{14}$. On avait dû, en Lorraine plus encore que dans d'autres régions, reconstruire de nombreuses églises au XIX ${ }^{\mathrm{e}}$ siècle ${ }^{15}$. L'apogée des constructions semble avoir été atteint, dans la Meurthe puis dans la Meurthe-et-Moselle, à la fin du Second Empire et pendant la première décennie de la Troisième République ${ }^{16}$. Vers 1880 , presque toutes les communes-paroisses se trouvaient pourvues d'églises récemment reconstruites, agrandies ou rénovées.

8 Le financement des constructions semble avoir principalement incombé aux fabriques, les communes se contentant le plus souvent de fournir gratuitement le terrain sur lequel devait s'élever ou s'étendre les constructions. La loi municipale du 5 avril 1884, qui 
imposa aux communes de disposer d'un lieu destiné à l'administration municipale et les dispensa simultanément de contribuer au financement des lieux de culte, n'introduisit donc pas une rupture radicale dans les faits, mais posa en principe la prééminence de la mairie sur l'église. Sans la rendre inéluctable, cette loi municipale anticipait en quelque sorte sur la séparation des Églises et de l'État ${ }^{17}$.

\section{La séparation des Églises et de l'État}

La séparation devait priver l'Église de son statut d'institution officielle, ce qui constituait pour les catholiques de Meurthe-et-Moselle une perspective des plus inquiétantes. Monseigneur Turinaz, qui occupait le siège épiscopal de Nancy depuis 1882, n'était pas du genre à accepter une telle mesure sans réagir. Il n'avait pas hésité, en 1903, à laisser des jésuites prêcher dans sa cathédrale, ce qui lui valut les foudres de Combes ${ }^{18}$. Lorsqu'un journaliste du Siècle l'interrogea l'année suivante au sujet de la séparation, il se déclara, en principe, "partisan de l'union des pouvoirs pour le bonheur du pays $»^{19}$. Il affirma cependant: "Du moment qu'on entame une lutte acharnée contre l'Église, je deviens partisan de la séparation ». À condition d'être "préparée et exécutée d'une façon loyale, libérale et juste ", une séparation lui paraissait "assurément préférable au régime de guerre et d'hostilité actuel ». Il réclamait notamment pour le diocèse la propriété de deux églises alors en cours de construction à Nancy, « sans aucun concours autre que celui des souscriptions volontaires $»^{20}$. Il affirmait en conclusion :

On me représente comme un évêque ultramontain et un adversaire de la République. C'est une erreur profonde. [...] Quant à la République, à l'institution en elle-même, je la mets au-dessus des actes qu'on fait en son nom et je suis très loin

d'être son adversaire... très loin...

Le pape Pie $\mathrm{X}$ a rejeté en bloc la séparation promulguée le 9 décembre 1905 qui rompait avec le concordat et interdisait, dans son article 2, le financement public des cultes ${ }^{21}$. Il interdit aux évêques de constituer les associations cultuelles prévues par la loi pour se substituer aux fabriques concordataires. Il a par la suite obstinément critiqué toutes les mesures prises par les gouvernements successifs pour trouver un terrain d'entente avec l' Église, rejetant la loi du 2 janvier 1907 sur l'exercice public des cultes et la loi du 28 mars 1907 sur les réunions publiques sans déclaration préalable aussi bien que la loi du 13 avril 1908 qui autorisait à nouveau les communes à financer les réparations des lieux de culte dont elles étaient propriétaires. Pendant toute cette période d'affrontement, l'évêque de Nancy se rangea systématiquement parmi les plus fidèles soutiens de la politique intransigeante du pape ${ }^{22}$. Il approuva notamment dans son diocèse, au début de l'année 1906, l'agitation contre les inventaires des biens des fabriques.

\section{L'avant-guerre}

11 Au début des années 1910, l'évêque de Nancy infléchit cependant sa position. Il rallia la majorité des évêques à son "programme de Nancy ", programme qui recommandait aux électeurs catholiques de voter pour les républicains modérés plutôt que pour les opposants au régime républicain. Il contribua ainsi à faire élire en Meurthe-et-Moselle plusieurs députés proches de Maurice Barrès ${ }^{23}$.

L'homme politique et écrivain d'origine lorraine était un catholique atypique mais ne se présentait pas vraiment comme un homme de compromis. Il considérait comme un 
devoir de défendre les églises contre les effets néfastes de la loi de séparation ${ }^{24}$. Et, dans sa série d'articles publiée à partir de janvier 1911 sous le titre de « Grande pitié des églises de France ", il n'hésita pas à mettre sur le même plan les partisans de la séparation et les Allemands, expliquant que la Lorraine était simultanément victime «des Prussiens qui détruisent notre langue; des sectaires qui détruisent notre religion, c'est-à-dire le langage de notre sensibilitée ${ }^{25}$ ». Mais, c'était là le point de vue d'un Lorrain installé à Paris, loin des réalités de la frontière.

La dégradation très rapide des relations franco-allemandes était lourde de menaces pour la Meurthe-et-Moselle. Après la crise de 1911 liée à la rivalité des deux puissances aux Maroc, les rumeurs de guerre et les incidents franco-allemands se multiplièrent dans le département. À l'issue d'un mois d'avril 1913 particulièrement tendu, celui qu'on appelait fréquemment « l'évêque de la frontière » lança dans les colonnes du journal catholique $L a$ Libre Parole un vibrant appel à l' "union nécessaire » de tous les Français anticipant en quelque sorte l'Union sacrée d'août $1914^{26}$.

\section{« La destruction de l'Église catholique » en Meurthe- et-Moselle}

14 La Meurthe-et-Moselle ne compte pas parmi les principaux champs de bataille de la première Guerre mondiale. Elle occupe cependant une place singulière dans l'histoire et l'historiographie du conflit. Les premières incursions allemandes sur le territoire du département ont eu lieu dès le début du mois d'août 1914. Nancy et Toul ont échappé à l'invasion, mais Pont-à-Mousson a été sévèrement bombardé et Lunéville a été brièvement envahi. Toute la moitié nord-est du département a été occupée du mois d'août 1914 au mois de novembre 1918. La Meurthe-et-Moselle a donc connu une invasion plus précoce et une occupation plus longue que n'importe quel autre département français. L'invasion allemande d'août 1914 a par ailleurs été particulièrement brutale, occasionnant la mort de plusieurs de plusieurs dizaines de milliers de soldats ainsi que celle d'au moins quatre cents civils ${ }^{27}$. Elle a aussi causé la destruction de plusieurs petites villes et celle de très nombreux villages.

Les curés et les églises n'ont pas été épargnés ${ }^{28}$. Dans une lettre pastorale du 2 février 1915, monseigneur Turinaz expliqua que les armées allemandes menaient, dans son diocèse, une "guerre d'extermination » défiant les conceptions des « apôtres aveugles du pacifisme $»^{29}$. Les Allemands s'étaient, selon lui, délibérément acharnés sur les lieux de culte catholiques : «Partout, c'est d'abord sur les églises que leurs obus sont dirigés; les prêtres catholiques ont été les plus insultés, les plus maltraités, quand ils n'ont pas été fusillés après de terribles tortures". L'évêque de Nancy évoquait le fait que : "À Gerbéviller, dans ce diocèse, après les plus horribles excès, dans l'église à moitié détruite, les soldats ont tiré, à bout portant, sur la porte du tabernacle qui leur résistait : le saint ciboire a été criblé de balles, qui ont mis en pièces ou en poussière les Saintes Espèces qu'il renfermait » (ill. 1 et 2). 
III. 1 : Guerre 1914-1917. Gerbéviller-la-Martyre. Ce qui reste de l'église paroissiale

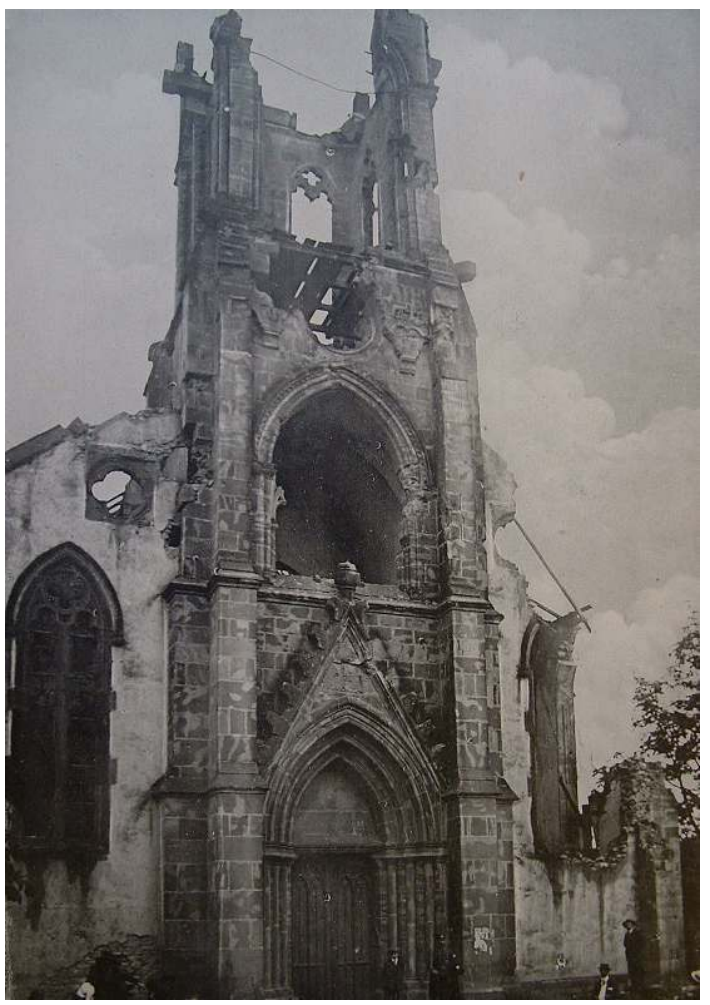

ADMM 2 FI 1672

CL. N. PADIOU

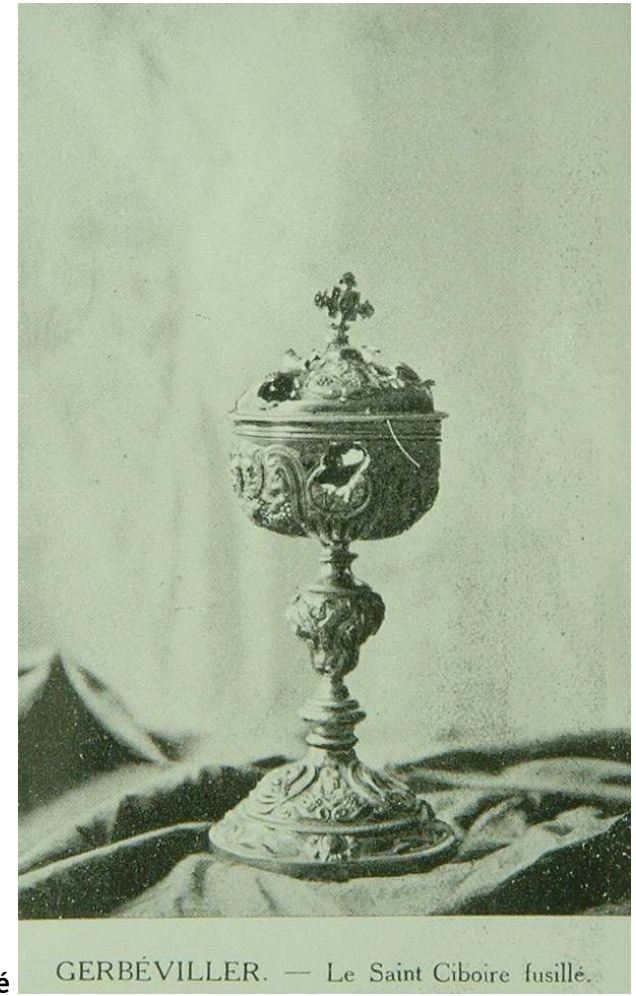

III. 2 : Gerbéviller. Le Saint Ciboire fusillé

GERBEVILLER. - Le Saint Ciboire fusille INVENTAIRE RÉgIONAL DE LORRAINE, CLICHÉ 81544391X

CL. N. PADIOU 
Il relevait comme une circonstance aggravante le fait que certains des Allemands sacrilèges étaient catholiques : "Des officiers se déclarent bons catholiques, des soldats montrent leur chapelets et leurs scapulaires, et aux reproches qui leur sont adressés, ils répondent: "C'est la guerre" ${ }^{130} »$. Il ne s'agissait pas seulement pour l'Allemagne d'exterminer « les Nations et les races déclarées inférieures et condamnées à mourir », il lui fallait aussi, à travers les curés et les églises, atteindre «à la destruction de l'Église catholique, de son autorité et de ses doctrines, à la destruction de toute religion ».

Cette lettre pastorale accusatrice connut un retentissement très important. Elle fut intégralement publiée dans $\mathrm{La}$ Guerre allemande et le catholicisme, un des principaux volumes de propagande antigermanique, publié sous la direction du recteur de l'Institut catholique de Paris, Monseigneur Baudrillart ${ }^{31}$.

\section{La contre-propagande des catholiques allemands}

Un certain J. A. Rosenberg, qui était professeur à l'université de Paderborn, se chargea de réfuter les accusations proférées dans La Guerre allemande et le catholicisme. En pensant manifestement à monseigneur Turinaz, il déplora que certains évêques français aient, "dans leurs lettres pastorales", attisé "l'imagination surexcitée à l'excès de leurs ouailles $»^{32}$. Il admettait que l'artillerie allemande avait pu bombarder des églises utilisées par les Français à des fins militaires, mais il niait l'idée que l'Allemagne eût mené la guerre aux églises ${ }^{33}$. Il lui semblait inévitable que les églises subissent des destructions dans les villes bombardées ${ }^{34}$. Et il affirmait d'ailleurs que les Français et les Belges n'auraient probablement pas hésité à détruire les églises allemandes s'ils en avaient eu l'occasion. Il en voulait pour preuve que :

Du reste, l'armée franco-anglo-belge ne s'est jamais beaucoup gênée de bombarder ses propres églises dès que les Allemands les employaient à des buts militaires ou si seulement on croyait qu'ils pussent les y employer ${ }^{35}$.

\section{La preuve par l'image des destructions d'églises}

La propagande ne s'est pas limitée aux discours. Elle s'est beaucoup appuyée sur les images. Les photographes français se sont efforcés d'apporter la preuve visuelle des destructions de lieux de culte. C'est ainsi que de très nombreuses images d'églises en ruines ont été publiées pendant toute la durée du conflit. On trouve par exemple des photographies prises en Meurthe-et-Moselle dans l'album illustré accompagnant La Guerre allemande et le catholicisme $e^{36}$. On en trouve aussi, en très grand nombre, dans la presse. Pour illustrer le vandalisme imputé aux troupes allemandes, le Bulletin de Meurtheet-Moselle choisissait au moins une semaine sur deux de mettre à la une la photographie d'une église en ruines. La presse nationale privilégiait, elle aussi, les images d'églises en ruines lorsqu'il s'agissait de convaincre l'opinion publique des ravages commis en Meurthe-et-Moselle ${ }^{37}$. Quant aux très nombreuses cartes postales publiées pendant le conflit, une sur deux environ montre une église. La légende insistait souvent sur la portée sacrilège des destructions, indiquant que l'église avait subi un "martyre», attirant l'attention sur un "saint ciboire fusillé » (ill. 2) ou signalant que le clocher n'avait subsisté que « par miracle » (ill. 3). 
III. 3 : La Guerre en Lorraine. Défense du Grand Couronné. Haraucourt.

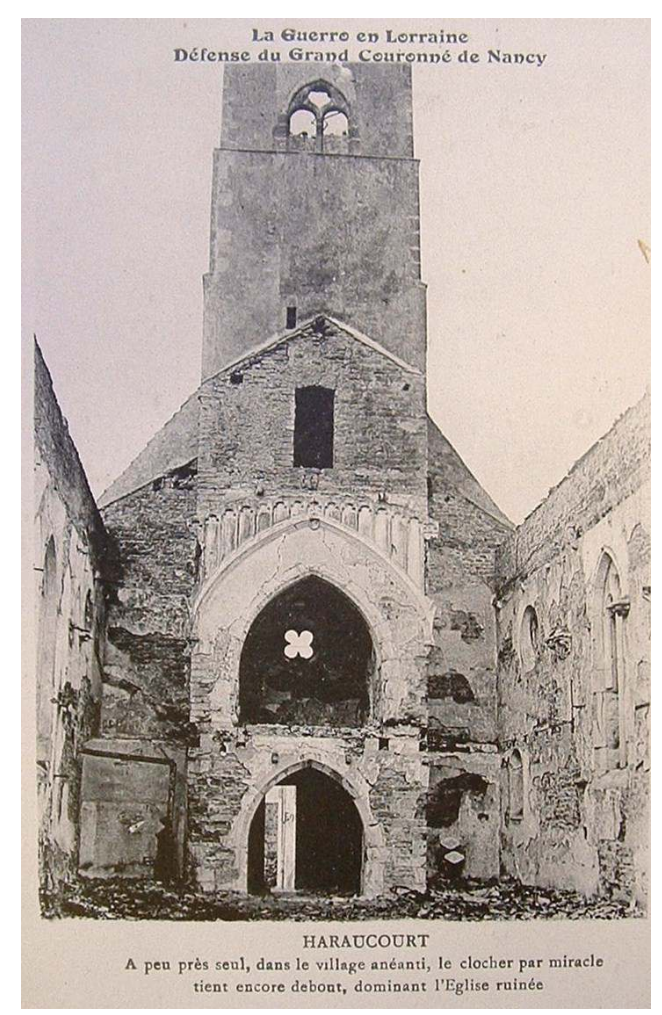

À PEU PRÈs SEUL, dANS LE VILLAge ANÉANTI, LE Clocher PAR MIRACLE TIENT ENCORE Debout, DOMINANT L'ÉgLISE RUINÉE, ADMM 2 FI 1680

CL. N. PADIOU

Les Allemands ont naturellement tenté de répliquer à la propagande illustrée française. Ils ont publié des photographies d'églises situées dans leur zone d'occupation, mais préservées des destructions (ill. 5 et 6). Ils ont aussi édité des cartes postales montrant des églises françaises détruites par les bombardements français (ill. 7). 
III. 4 : En Lorraine. Guerre 1914. Environs de Lunéville. Hériménil. L'église après le bombardement.

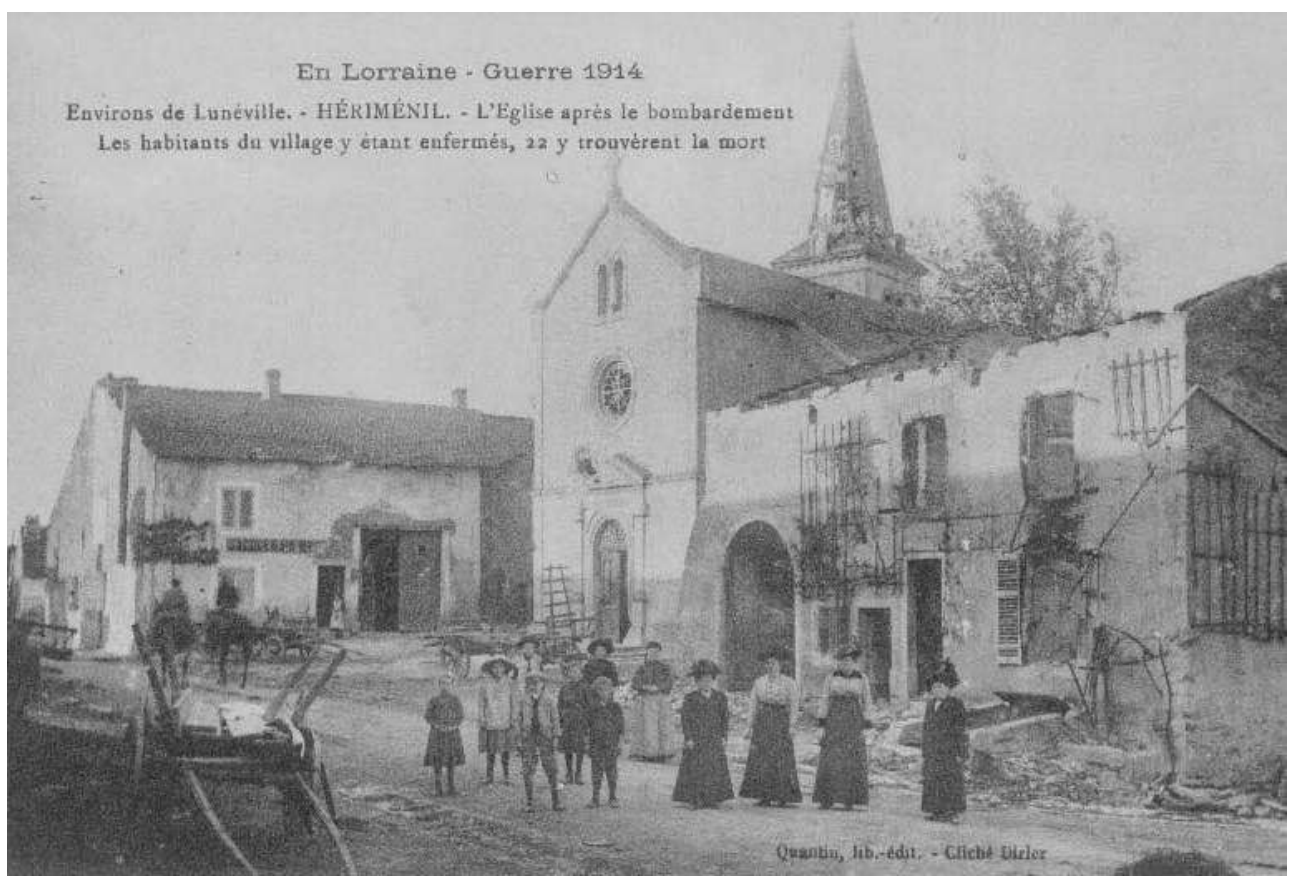

LES HABITANTS DU VILLAgE Y ÉTAIENT ENFERMÉS, VINGT-DEUX Y TROUVÈRENT LA MORT, BIBLIOTHÈQUE MUNICIPALE DE NANCY

CL. N. PADIOU

III. 5 : Schönung einer Kirche trotz Verwüstung in Vigneulles [Préservation d'une église malgré les dévastations à Vigneulles]

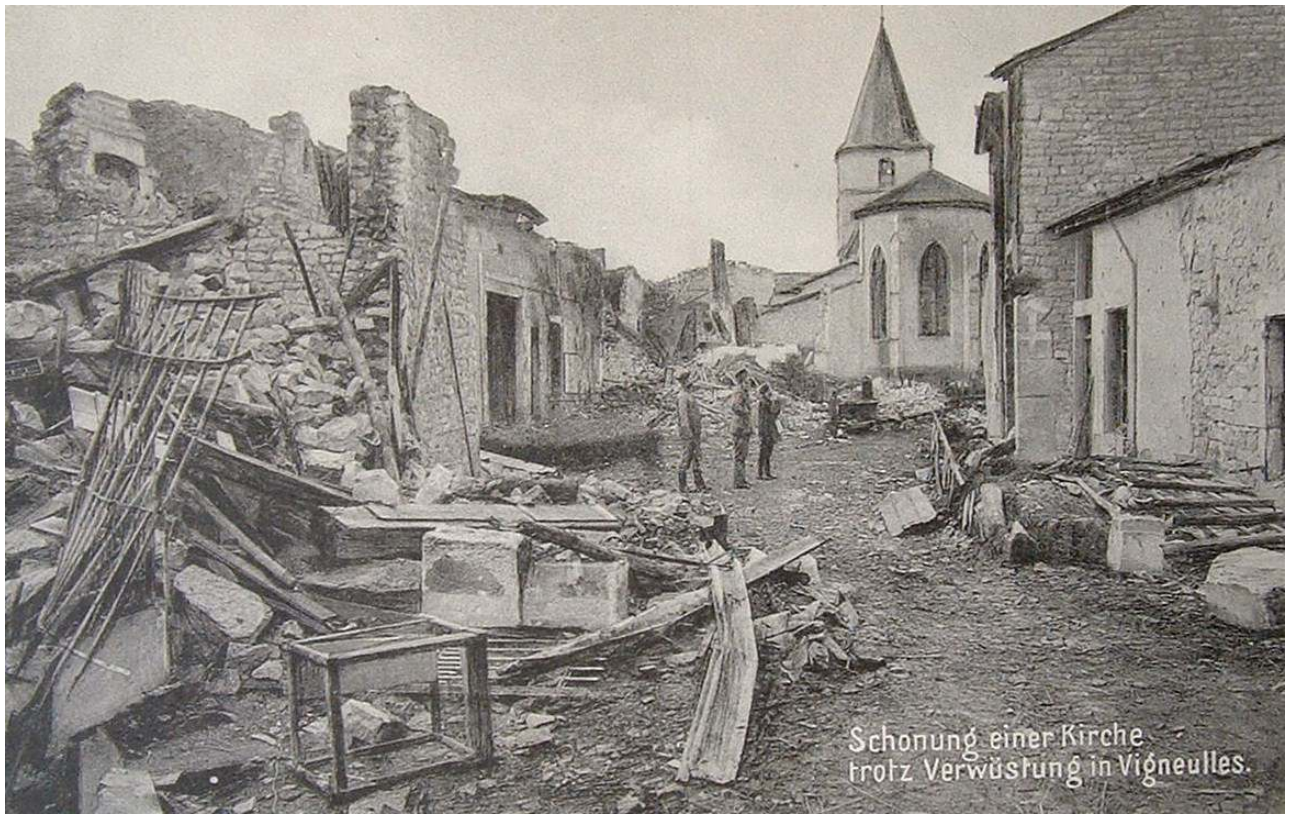

ADMM 2 Fi 4257

CL. N. PADIOU 
III. 6 : Mars-la-Tour. Inneres der Kirche im Weihnachtsschmücke, 1914 [Intérieur de l'église décoré pour Noël]

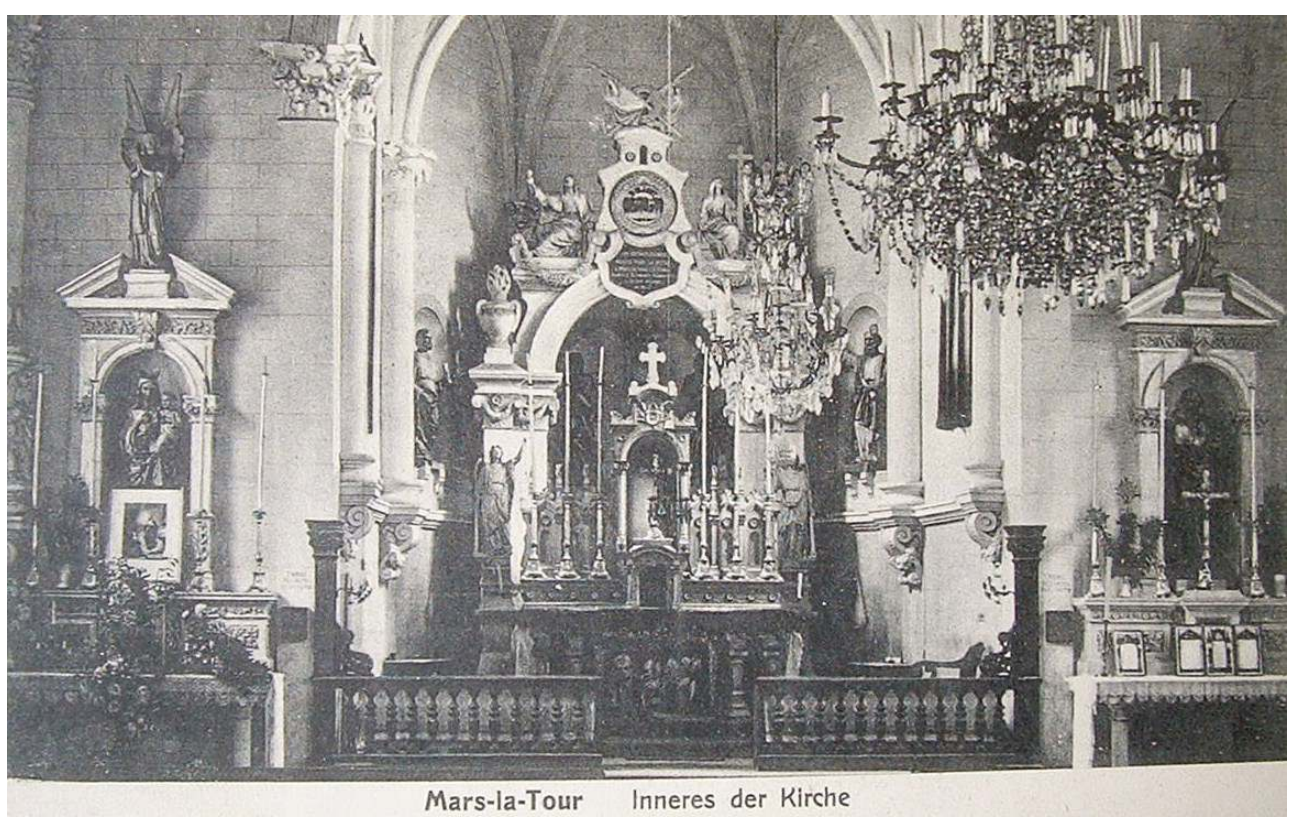

ADMM 2 FI 4284

CL. N. PADIOU

III. 7 : Longwy - Kirche. Kreuzabnahme Christi von Dupain. Geschenkt vom französischen Staat 1880, gemalt 1877. Das wertvolle Gemälde ist ziemlich verletzt [Longwy - Église. Descente de croix de Dupain. Offert par l'État français en 1880, peint en 1877. Le précieux tableau est passablement endommagé].

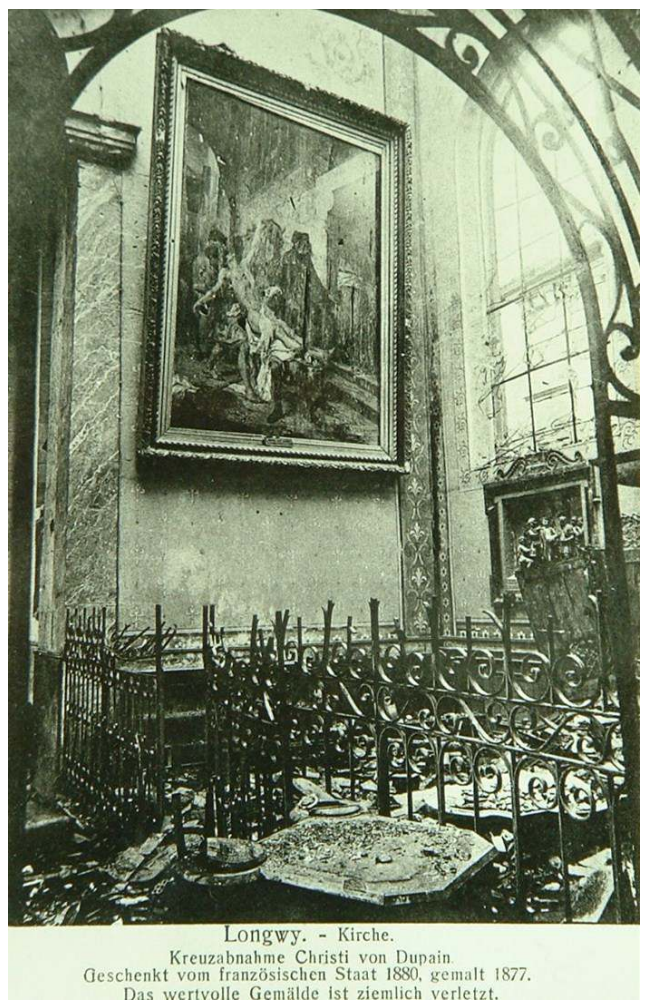

Cl. Inventaire régional, cliché $n^{\circ}$ 895400185XD. 


\section{Le bilan global des destructions}

21 de plus de quatre ans d'occupation et quelques seulement semaines après la mort de monseigneur Turinaz. L'heure était venue de dresser le bilan définitif des destructions. L'évêché de Nancy s'était préoccupé, dès 1915, d'établir le «martyrologue » des églises détruites dans le diocèse, en recensant, dans chaque doyenné, la liste "des églises bombardées, mutilées, incendiées, pillées, dévastées, anéanties $\aleph^{38}$. Mais, l'enquête ne put avoir lieu qu'après l'armistice. Elle établit que 219 des 538 paroisses du diocèse avait été détruites. 101 églises étaient considérées comme entièrement détruites par l'évêché, 106 comme partiellement détruites ${ }^{39}$. Afin d'estimer le montant des réparations que la France devrait réclamer à l'Allemagne, la préfecture de Meurthe-et-Moselle s'appliqua à calculer le pourcentage de destruction dans chacune des communes du département. Elle estima pour sa part à 63 le nombre des églises paroissiales détruites pendant le confli ${ }^{40}$.

En combinant toutes ces statistiques, on s'aperçoit que les églises ont été complètement détruites dans une dizaine de villages épargnés par les destructions. Mais, un nombre à peu près égal de communes présente le cas inverse : l'église y a été préservée malgré la destruction générale de l'agglomération. Grosso modo, la liste des églises détruites recoupe donc celle des communes ayant le plus souffert de la guerre ${ }^{41}$.

De nombreux témoignages ont corroboré, après-guerre, les rumeurs selon lesquelles les Allemands avaient transformé les églises en temples protestants, en hôpitaux de campagne, en casernes, en écuries et même en prisons ${ }^{42}$. Les dossiers de dommages de guerre expliquaient que les Allemands avaient construit des bunkers dans certaines églises et s'apprêtaient à en faire sauter d'autres au moyen de mines ${ }^{43}$. Les preuves avancées par les architectes paraissent très ténues, notamment pour ce qui concerne les mines $^{44}$. Elles ne doivent cependant pas être rejetées en bloc: dans la mesure où il fournissait un poste d'observation ou un point de mire remarquable, un clocher pouvait revêtir une réelle importance stratégique, et pas seulement pour les Allemands. Les dossiers de dommages de guerre témoignent en effet du fait que les Français ne se sont pas comportés très différemment des Allemands : ils n'ont pas hésité à cantonner des troupes dans les églises situées près du front, à installer dans leurs clochers des postes d'observation ou des batteries anti-aériennes ${ }^{45}$. Il est possible et même probable que les Allemands aient incendié quelques églises pendant l'invasion de la Meurthe-et-Moselle et il n'est pas impossible qu'ils aient miné quelques clochers avant d'évacuer le département. Mais, la plupart des églises ont été probablement détruites par des bombardements d'artillerie, et ces bombardements étaient français aussi bien qu'allemands.

24 En dépit de l'article 27 de la IV convention de La Haye du 18 octobre 1907 qui prévoyait la protection des lieux de culte en cas de guerre, la France et l'Allemagne n'ont apparemment fait aucun effort pour épargner les églises ${ }^{46}$. Le mépris des engagements pris avant le conflit était général, mais la carte de guerre avait placé les Allemands et les Français dans des situations fondamentalement asymétriques: les soldats français pouvaient détruire les églises en ayant la conviction d'accomplir un sacrifice héroïque de leur propre patrimoine, cependant que leurs homologues allemands placés en position d'envahisseurs pouvaient difficilement justifier les destructions qu'ils occasionnaient ${ }^{47}$. 


\section{Le souvenir des destructions}

Allemands par leurs adorations réparatrices au pied de l'autel restauré $\aleph^{52}$. Lors de la consécration de l'autel majeur de Longwy-Haut, en 1926, le curé rappela lui aussi que les Allemands s'étaient acharnés sur l'église :

Dans l'universelle dévastation, l'église ne fut pas épargnée: tour mutilée, murs ébréchés, autels réduits en poussière, orgue anéanti, cloches brisées, immense désolation régnant dans le lieu saint. L'ennemi voulut encore ajouter aux horreurs du bombardement, en brûlant la première nuit de l'occupation les bancs de l'église, en mutilant le chemin de la Croix, en perçant de balles une statue de la Vierge, relique que nous conservons pieusement ${ }^{53}$.

Le curé de Prény souligna, pour sa part, que les Allemands avaient commis dans sa paroisse un « acte de vandalisme sacrilège » prémédité :

Pendant la guerre, les Allemands firent, durant de longs mois, des travaux mystérieux en dessous de l'église; c'était, disaient-ils, pour un abri de bombardement ; mais, les misérables, ils la minaient formidablement, et sans aucun but stratégique raisonnable. En septembre 1918, au moment de l'évacuation des habitants en Belgique, l'église était toujours debout, à peine touchée par les obus. Quelques semaines plus tard, elle n'était plus qu'un tas de pierres, sauf le pourtour du chœur qui, bâti sur le roc, avait résisté à la puissante explosion ; les fondations elles-mêmes étaient détruites et il fallut creuser des puits et couler du béton pour faire la nouvelle construction... ${ }^{54}$

Quant au curé de Pannes, il insista sur le « douloureux calvaire » subi par sa paroisse ${ }^{55}$. Il rappela que six civils avaient été tués pendant l'invasion allemande du 20 septembre 1914, que la population avait été enfermée dans l'église où elle avait assisté à un 
«horrible sacrilège » quand un soldat allemand avait éventré «à coup de pioche le tabernacle » avant que le commandant de la place ne "profane les Saintes-Espèces ». À l'issue d'une «longue captivité » dans l'église privée de vitres, "dans les brouillards, gelées et pluies d'automne », deux vieillards étaient morts « l'un sous le grand Christ et l'autre sous la chaire à prêcher ». Après avoir fait sauter le clocher de l'église, le 30 juillet 1917, les soldats allemands avaient jeté à bas les statues et lancé « du milieu de la grande nef des projectiles contre les stations du chemin de croix ", ils avaient détruit le mobilier pour en faire du «bois à brûler» avant de pénétrer dans la sacristie "pour finir leurs horreurs ». L'évêque décrivit quant à lui l'église de Pannes comme un "véritable camp de martyrs » dans lequel « pasteur et fidèles ont souffert ensemble » et où « Dieu lui-même a été crucifié à nouveau dans son tabernacle $»^{56}$.

\section{L'humanisation des églises}

Les églises avaient parfois été assimilées, pendant la guerre, à des soldats français et même à des victimes civiles de la guerre. La reconstruction des églises et les cérémonies de consécration fournirent, en Meurthe-et-Moselle, l'occasion de renouveler et même de développer ce type de comparaisons. Le chanoine Thouvenin expliqua, en juillet 1921, que les églises réparables du diocèse portaient des «blessures de guerre $»^{57}$. L'église de Bionville avait, d'après son curé, subi «la blessure la plus douloureuse ${ }^{58}$. Celle de Nomeny avait reçu « de nombreuses et graves blessures", pendant les trois premières années de la guerre, avant d'être détruite par l'artillerie allemande : trois des cinq nefs avaient été abattues « avec leurs colonnes et leurs doubleaux tombés en ordre, peut-on dire, comme sur le champ de bataille la mitrailleuse alignait les cadavres d'une charge bien rangée $e^{59}$ ». Quant à la destruction du clocher de l'église de Pannes par les Allemands, elle fut assimilée par le curé de la paroisse à une véritable "décapitation ${ }^{60}$. Le vicaire général du diocèse avait, dès 1919, filé la métaphore combattante en définissant les églises du diocèse comme des "saintes blessées de la guerre [...] des blessées, des mutilées, frappées au champ d'honneur comme nos soldats, et trop souvent comme eux mortellement atteintes, nobles victimes d'une barbarie qui à la destruction brutale organisée a joint le sacrilège voulu ${ }^{61} »$.

31 Les ruines d'églises avaient presque entièrement disparu du paysage, mais le souvenir des destructions « sacrilèges » restait donc très présent dans les esprits et était régulièrement réactivé lors de chaque cérémonie de consécration. Ce souvenir semble s'être estompé après la deuxième Guerre mondiale qui avait elle-même apporté son lot de destructions ${ }^{62}$. Le ciboire de Gerbéviller a cependant été présenté, en 1994, dans le cadre d'une exposition qui commémorait le quatre-vingtième anniversaire de l'invasion du département et le "martyre des villages lorrains " $^{63}$. Et cet objet symbolique demeure exposé dans l'église paroissiale, accompagné d'un cartel qui en présente l'histoire, dans les mêmes termes que ceux qu'avait employés, en 1915, l'évêque de Nancy.

\section{L'évolution de la place symbolique des églises pendant la guerre}

Dès 1919, les statistiques préfectorales et diocésaines attestèrent que les églises n'avaient pas été plus touchées que la moyenne des bâtiments de Meurthe-et-Moselle situés dans la 
zone des combats. Le clergé lorrain a cependant continué, au moins jusqu'à la fin des années 1920, à imputer aux troupes allemandes une volonté de vandalisme sacrilège. C'est en grande partie grâce à la persistance de cette interprétation largement erronée des enjeux de la guerre que les églises purent faire l'objet d'un large consensus après le conflit, alors qu'elles avaient suscité de nombreux antagonismes entre 1905 et 1914.

Une telle évolution de la place symbolique des églises relativise l'importance qu'on doit accorder au statut officiel des édifices. Tout en demeurant la propriété des communes, les églises avaient en effet perdu, à partir de la séparation des Églises et de l'État, une grande partie du prestige autrefois attaché à la pratique d'un culte concordataire. Elles constituèrent cependant un thème central de la propagande de guerre, et pas seulement pour les catholiques. On pourrait penser que cette importance était liée à la place jouée par les églises dans le « culte moderne des monuments » ${ }^{64}$.Mais, il faut aussi tenir compte des contradictions de l'État français dans ce domaine: l'article 12 de la loi sur les dommages de guerre prévoyait des mesures spécifiques de reconstruction pour les " édifices cultuels et civils ", rassemblant ainsi dans la même catégorie les mairies et les églises que la loi municipale de 1884 et la loi de séparation s'étaient pourtant évertuées à distinguer.

\section{NOTES}

1. Cf. notamment Reconstructions et modernisation. La France après les ruines. 1918-1945, Paris, Archives nationales, 1991, $310 \mathrm{p}$.

2. Pour la Picardie, cf. Jean-Charles Cappronier, «Les églises reconstruites après la Grande Guerre » dans Reconstructions en Picardie après 1918, Paris, Réunion des musées nationaux, 2000, 312 p., p. 150-181 et Céline Frémaux, La Reconstruction dans l'est de la Somme. L'architecture religieuse et son décor, Région Picardie-Inventaire général, 64 p. Pour les églises du Pas-de-Calais, cf. Jean-Pierre Blin, «Les églises de la reconstruction, entre éclectisme et modernité » dans Éric Bussière, Patrice Marcilloux, Denis Varaschin (dir.), La Grande reconstruction. Reconstruire le Pas-de-Calais après la Grande Guerre, Arras, Archives départementales du Pas-de-Calais, 2002, 478 p., p. 323-337.

3. Cf. Annette Becker, La Guerre et la foi. De la mort à la mémoire. 1914-1930, Paris, Armand Colin, 1994, 142 p., notamment p. 21 et p. 41, et Annette Becker « Les artistes, la guerre, le sacré » dans Jean-Jacques Becker (dir.), Histoire culturelle de la Grande Guerre, Paris, Armand Colin, 2005, 272 p., p. 125-138, en particulier p. 128-129.

4. Cf. par exemple Jean-Michel Leniaud, « Entre la grue de Cologne et le marteau de Thor : les cathédrales au temps des nations ", dans Jean-Michel Leniaud, La Révolution des signes. L'art à l'église (1830-1930), Paris, Le Cerf, 2007, 430 p., p. 117-134.

5. Jean-Charles Cappronier évoque ainsi le "caractère de barbarie sacrilège » des troupes allemandes actives en Picardie, cf. Cappronier, op. cit., p. 81.

6. Christina Kott estime qu'il est pratiquement impossible d'établir l'ampleur des destructions et privilégie délibérément l'étude de l'impact des destructions sur l'opinion 
publique, cf. Christina Kott, Préserver l'art de l'ennemi ? Le patrimoine artistique en Belgique et en France occupées. 1914-1918, Bruxelles, P.I.E. Lang, 2006, 442 p., p. 43-44 et note 55, p. 73.

7. L'ensemble du fonds des dommages de guerre représente près de $150 \mathrm{ml}$ d'archives. Ces dossiers fournissent de précieux renseignements sur la destruction et la reconstruction des églises. Ce fonds a été très peu exploité par les historiens, qui n'ont par ailleurs pas étudié dans leur ensemble les textes et images concernant les églises détruites dans le département. On peut seulement mentionner, comme piste historiographique, une étude bien informée mais succincte, publiée par l'historien Claude Gérard, cf. Claude Gérard, « III. Des villages témoins, une blanche floraison d'églises ", Villages lorrains, n78, printemps 1997, p. 16-22.

8. Cf. François Roth (dir.), L'Encyclopédie illustrée de la Lorraine. Histoire de la Lorraine. L'époque contemporaine, t.1: De la Révolution à la Grande Guerre, Nancy, Presses Universitaires de Nancy, 1992, 274 p.

9. Cf. François Baudin, Histoire économique et sociale de la Lorraine. 2. L'Essor, Nancy-Metz, Presses universitaires de Nancy-Serpenoise, 1993, 290 p.

10. Sur les villages traditionnels lorrains, cf. Claude Gérard, Jean Peltre, Les Villages lorrains, Nancy, Publications de l'université de Nancy II, 1978, 106 p. et surtout Claude Gérard, Architecture rurale française. Lorraine, Paris, Berger-Levrault, 1981, 346 p. On peut aussi consulter les quelques pages écrites à ce sujet par Paul Léon pendant la guerre, cf. Paul Léon, La Guerre et l'architecture. La Renaissance des ruines. Maisons, monuments, Paris, Henri Laurens, 1918, 94 p. et 24 pl. hors-texte, p. 26-30. Sur la lenteur de la reconstruction en Lorraine après la Guerre de Trente ans, cf. Martine Bontemps-Litique, «Les destructions suite à la guerre de Trente ans dans les baillages d'Allemagne et des Vosges » dans Guy Cabourdin, Jean Lanher (dir.), Villages et maisons de Lorraine. Actes du colloque de Nancy (22-24 octobre 1981), Metz-Nancy, Serpenoise-Presses universitaires de Nancy, 1982, 238 p., p. 217-224.

11. Cf. à ce sujet Philippe Boutry, «Le clocher » dans Pierre Nora (dir.), Les Lieux de mémoire. III Les France, vol. 2 « Traditions », Paris, Gallimard, 1992, 988 p., p. 57-89, notamment p. 67.

12. Sur l'importance sociale et politique du catholicisme en Lorraine vers 1900 , cf. Serge Bonnet, Sociologie politique et religieuse de la Lorraine, cahier de la fondation nationale des sciences politiques n¹81, Paris, Armand Colin, 508 p., p. 100.

13. Sur les églises reconstruites en Lorraine après la Guerre de Trente ans, cf. Émile Badel, « La $2^{\mathrm{e}}$ aux architectes ", L'Immeuble et la construction dans l'Est, 19 mars 1922.

14. L'église médiévale de Saint-Epvre de Nancy a par exemple beaucoup souffert du manque d'entretien avant et pendant la période révolutionnaire, cf. Nicolas Padiou, Les Enjeux d'un grand projet néogothique. La reconstruction de l'église Saint-Epvre de Nancy, 1863-1871, maîtrise d'histoire de l'art sous la direction de François Pupil, Nancy, Institut d'histoire de l'art, faculté de lettres de l'université de Nancy II, 1999, 130 p., p. 13-14.

15. Sur les nombreuses reconstructions d'églises en Lorraine pendant la période concordataire, cf. Jean-Michel Leniaud, Vingt siècles d'architecture religieuse en France, Paris, CNDP, 2007, 268 p., p. 17.

16. Les archives diocésaines conservées aux archives départementales contiennent des statistiques sur les églises reconstruites au XIX ${ }^{\text {e }}$ siècle, cf. Arch. dép. Meurthe-et-Moselle $50 \mathrm{~J}$ I 24-03.

17. Jean Michel Leniaud évoque, pour le dernier tiers du XIX ${ }^{\mathrm{e}}$ siècle, un «contexte préséparatiste ", cf. Jean-Michel Leniaud, "La basilique du Sacré-Cœur entre concordat, état confessionnel et séparation. La loi d'utilité publique (24 juillet 1873), vote et abolition », dans Leniaud, La Révolution des signes, op. cit., p. 215. 
18. Jean Baubérot, La Laïcité, 1905-2005, entre passion et raison, Paris, Le Seuil, 2004, 280 p., p. 94.

19. 1905, la séparation des églises et de l'état. Les textes fondateurs, présentation de Dominique de Villepin, Paris, Perrin, 2004, 476 p., p. 181-182. L'évêque de Nancy n'était pas une exception, René Rémond explique que «refus catégorique de la sécularisation et attachement indéfectible à l'union la plus étroite entre religion et société demeurent dans les premières décennies du $\mathrm{XX}^{\mathrm{e}}$ siècle l'objectif de l'Église catholique, même après qu'elle eut pris quelque distance par rapport à l'intransigeantisme du XIX ${ }^{\mathrm{e}}$ siècle ", cf. René Rémond, Religion et société en Europe, Religion et société en Europe. La sécularisation aux XIX et XX $X^{e}$ siècles (1789-1998), Paris, Le Seuil, 1998, 308 p., p. 218-219.

20. On peut supposer qu'il évoquait l'église Saint-Joseph et l'église du Sacré-Cœur. L'église SaintJoseph avait été commencée en 1890 sur des plans de l'architecte Léopold Hardy, mais ce dernier était mort en 1894 avant d'avoir pu achever l'édifice et l'église n'avait toujours pas de tour en 1904. L'église du Sacré-Cœur avait été commencée sur des plans de l'architecte Antoni Rougieux en 1902 et fut consacrée par monseigneur Turinaz le 15 novembre 1905, un an après l'interview donnée par lui au Siècle et quelques semaines seulement avant le vote de la loi de séparation, l'édifice était cependant loin d'être achevé à cette date, cf. "Les nouvelles églises de Nancy ", L'Immeuble et la construction dans l'Est, 31 mai 1931.

21. Sur les réactions du pape au vote de la loi de séparation, cf. notamment Jean-Paul Scot, "L'État chez lui, l'Église chez elle ». Comprendre la loi de 1905, Paris, Le Seuil, 2005, 390 p.

22. Christian Sorrel, "Les évêques à l'heure de la Séparation ", dans Jean-Pierre Chantin, Daniel Moulinet (dir.), La Séparation de 1905. Les hommes et les lieux, avant-propos de JeanMarie Mayeur et postface d'Émile Poulat, Paris, éditions de l'Atelier-Éditions ouvrières, 2005, 272 p., p. 52-66, notamment p. 56-57.

23. Gérard Cholvy, Yves-Marie Hilaire, Histoire religieuse de la France contemporaine. 1880-1930, Toulouse, Privat, 1986, 452 p., p. 154 et p. 194 ainsi que Sorrel, «Les évêques à l'heure de la Séparation », dans Chantin, Moulinet (dir.), La Séparation de 1905, op. cit., p. 62.

24. Pellier M., «Le sentiment religieux chez Barrès ", Le Pays lorrain, 1926, p. 410-416 et Zeev Sternhell, Maurice Barrès et le nationalisme français, Paris, Complexe, 1985, 396 p., p. 370.

25. Maurice Barrès, La Grande Pitié des églises de France, dans L'Euvre de Maurice Barrès, t.VIII, 514 p., p. 14.

Paul Vergnet, « Français, tournez-vous vers la frontière », La Semaine religieuse du diocèse de Nancy et deToul, 7 juin 1913, p. 460-463. Cet article avait été publié initialement dans La Libre parole du 29 mai 1913.

26.

27. Sur les pertes militaires considérables pendant les mois d'août et septembre 1914, cf. Jean-Jacques Becker, « Lorraine sanglante » dans 14-18, La Très Grande Guerre, Paris, Le Monde éditions, 1994, 278 p., p. 65-71. Sur les victimes civiles de l'invasion, cf. John Horne, Alan Kramer, 1914. Les atrocités allemandes, Paris, Tallandier, 2005, 640 p.

28. D'après les archives de l'évêché, une dizaine de curés du diocèse auraient été tués lors du conflit, essentiellement pendant l'invasion, cf. «Prêtres non mobilisés fusillés par les Allemands sans raison depuis les débuts de la guerre », Arch. dép. Meurthe-et-Moselle, 50 J I 27-05.

29. «Actes officiels. Lettre pastorale de Monseigneur l'archevêque-évêque de Nancy et de Toul sur la guerre actuelle, ses caractères et ses conséquences ", La Semaine religieuse du diocèse de Nancy et de Toul, 6 février 1915, p. 63-74, p. 65.

30. Le nord de la Meurthe-et-Moselle a été occupé par des troupes du Wurtemberg majoritairement protestantes. Le sud-est du département a, en revanche, été occupé par des troupes essentiellement bavaroises et donc majoritairement catholiques. 
31. Alfred Baudrillart (dir.), La Guerre allemande et le catholicisme, Paris, Bloud et Gay, 1915, 304 p., p. 242-252. Veuillot citait à plusieurs reprises, cf. Veuillot, « La guerre aux églises et aux prêtres »; Ibid., p. 94 et p. 99-101 ainsi que p. 104 et p. 117.

32. La Guerre allemande et le catholicisme. Réponse allemande aux attaques françaises. Éditée par des catholiques allemands, Amsterdam-Rotterdam, C. L. van Langenhuysen, 1915, 140 p., p. 54-55.

33. "Lorsqu'une église sert de repaire à une population armée, lorsque son clocher abrite un poste d'observation, lorsque des signaux en sont donnés, lorsque des mitrailleuses envoient de là leurs balles meurtrières, le canon doit faire son œuvre, c'est évident »; Ibid., p. 63. Il affirmait un peu plus loin: «Dans les manuels militaires anglais trouvés par les Allemands, l'emploi des clochers est justement recommandé comme offrant de bons points d'observation. »

34. «D'ailleurs, une église est toujours exposée dans une ville bombardée. Pourquoi l'épargnerait-on? Là où la guerre exerce ses ravages, la destruction marche de paire »; Ibid., p. 107.

35. Ibid., p. 63.

La Guerre allemande et le catholicisme. Album no1. Documents photographiques illustrant la conduiterespective des armées allemandes et françaises à l'égard de l'Église catholique, Paris, Bloud et Gay, 1915, 32 p. La page 17 présente une photographie du clocher de l'église de Serres. Le chapitre III, portant sur les « Attentats sacrilèges ", montre une photographie d'un « Christ scié par les soldats allemands » à Drouville (p. 21) ainsi que le « Tabernacle cambriolé » et le « Saint Ciboire fusillé » de Gerbéviller (p. 28).

36.

37. Voir par exemple les quatre photographies: «Après la bataille. Des ruines. L'église de Réméréville a été bombardée. Les obus ont détruit l'église de Drouville. Le village de Maixe a vu les barbares. - Au centre, les ruines de l'église d'Haraucourt », Le Pays de France, 7 janvier 1915, p. 17.

38. Cf. "Martyrologue des églises du diocèse de Nancy ", Arch. dép. Meurthe-et-Moselle $50 \mathrm{~J}$ I 27-05.

39. «Statistique des paroisses et annexes, des églises, des presbytères et des maisons d'œuvres ruinés, dévastés ou fortement endommagés par la guerre ", La Semaine religieuse du diocèse de Nancy et de Toul, 12 avril 1919, p. 230-238.

40. Société coopérative de reconstruction des églises du diocèse de Nancy, Assemblée générale du 16 janvier 1922, Nancy, ancienne imprimerie Vagner, 1922, 16 p., p. 9.

41. D’après les statistiques préfectorales, 25 communes du département avaient été détruites à plus de $90 \%$. Parmi ces communes, 24 avaient vu leur église complètement détruite pendant la guerre.

42. Ce fut le cas dans l'église d'Avril, cf. « Ça et là dans le diocèse ", La Semaine religieuse du diocèse de Nancy et de Toul, 4 janvier 1919, p. 8-11. Sur les églises utilisées pour des offices protestants, cf. " Nouvelles de la partie envahie [du diocèse] », La Semaine religieuse du diocèse de Nancy et de Toul, 5 octobre 1918, p. 599-600. Sur les « ambulances » ou les « lazarets » installés dans les églises, cf. le cas des églises de Pierrepont et Ville-au-Montois, "Quelques nouvelles de la partie du diocèse occupée par l'ennemi », La Semaine religieuse du diocèse de Nancy et de Toul, 9 juin 1917, p. 360-363. Sur les cantonnements de troupes allemandes, cf. « Ça et là dans le diocèse ", La Semaine religieuse du diocèse de Nancy et de Toul, 4 janvier 1919, p. 8-11. Sur les stockages de munitions, cf. « Ça et là dans le diocèse ", La Semaine religieuse du diocèse de Nancy et de Toul, 22 février 1919, p. 125-126. Pour les prisons, cf. le cas des églises de Landres et de Piennes, "Ça et là dans le diocèse ", $L a$ Semaine religieuse du diocèse de Nancy et de Toul, 25 janvier 1919, p. 52-55.

43. L'architecte Thomas évoque un "formidable abri blindé " installé par les Allemands dans l'église de Raucourt, « Notice du 3 août 1922 ", Arch. dép. Meurthe-et-Moselle 10 R 822. Après le vote d'une loi sur les dommages de guerre, le 17 avril 1919, les maires, les curés et de nombreux 
architectes ont collaboré à l'établissement de dossiers destinés à permettre la reconstruction ou la réparation des lieux de culte. Ces dossiers de dommages de guerre fournissent de précieux renseignements sur les circonstances de la destruction des églises et sur les divers usages de ces édifices pendant le conflit.

44. On trouve mention de sapes allemandes destinées à faire sauter le clocher de l'église de Prény dans «Dossier de dommages de guerre de l'église de Prény, 14 décembre 1920 », Arch. dép. Meurthe-et-Moselle $10 \mathrm{R}$ 821. Dans d'autres documents, l'explosion de l'église à la veille de l'armistice est attribuée à une erreur de l'artillerie américaine, cf. «Église de Prény. Travaux imprévus de fondation faisant l'objet d'une demande d'indemnité supplémentaire à la commission cantonale. Déclaration de $\mathrm{M}$. André, architecte à Nancy, chargé de la reconstruction de l'église de Prény » [1923], Arch. dép. Meurthe-et-Moselle 10 R 821.

45. Cf. par exemple le cas de l'église de Mousson, "Constat du 26 février 1921 », Arch. dép. Meurthe-et-Moselle $10 \mathrm{R}$ 797. La légende de l'illustration 4 du présent article laisse penser que les Allemands avaient séquestré des civils dans l'église du village d'Hériménil. On peut supposer que les Allemands n'ont pas bombardé un village occupé par leurs propres troupes, il y a donc tout lieu de croire que les 22 personnes tuées dans l'église d'Hériménil ont été victimes d'un bombardement français.

46. $\mathrm{La}$ « $\mathrm{IV}^{\mathrm{e}}$ convention sur les lois et les coutumes de la guerre» avait été signée par la France aussi bien que par l'Allemagne. L'article 27 de cette convention indiquait: " Dans les sièges et bombardements, toutes les mesures nécessaires doivent être prises pour épargner, autant que possible, les édifices consacrés aux cultes, aux arts, aux sciences et à la bienfaisance, les hôpitaux et les lieux de rassemblement de malades et de blessés, à condition qu'ils ne soient pas employés en même temps à un but militaire. Le devoir des assiégés est de désigner ces édifices ou lieux de rassemblement par des signes visibles spéciaux qui seront notifiés d'avance à l'assiégeant ». Sur la convention de La Haye, cf. Arsène Alexandre, Les Monuments français détruits par l'Allemagne, Paris-Nancy, Berger-Levrault, 1918, 220 p., p. 12 et p. 30. Cf. aussi « Annexe à la IV convention de La Haye (18 octobre 1907) concernant les lois et coutumes de la guerre sur terre » dans Horne, Kramer, 1914. Les Atrocités allemandes, op. cit., p. 490 et Kott, Préserver l'art de l'ennemi, op. cit, p. 51-54.

47. Les Français n'ont pas pénétré sur le territoire allemand, sauf en Alsace où ils ont endommagé quelques églises qui pouvaient d'ailleurs passer pour françaises dans une perspective de reconquête de l'Alsace-Lorraine.

48. Sur le concept de "démobilisation culturelle », cf. 14-18 Aujourd'hui-Today-Heute, revue annuelle d'histoire, $\mathrm{n}^{\circ} 5$ "Démobilisations culturelles après la Grande Guerre ", Paris, Noêsis, 2002, 252 p. Christina Kott explique que, après la signature de l'armistice, «le patrimoine artistique dans son ensemble reste donc "mobilisé" en tant qu'enjeu dans les négociations de paix, tout comme objet d'identification nationale », cf. Kott, Préserver l'art de l'ennemi, op. cit., p. 400. Les éditeurs de cartes postales continuèrent, longtemps après la fin de la guerre, à publier des photographies d'églises en ruines et même des photographies d'églises dans leur état d'avant-guerre.

49. Ce récit est rapporté dans « Bénédiction des église de Beaumont et d'Hamonville », La Semaine religieuse du diocèse de Nancy et de Toul, 18 octobre 1924, p. 652-653.

50. «La bénédiction de l'église de Domèvre-sur-Vezouze ", La Semaine religieuse du diocèse de Nancy et de Toul, 3 février 1923, p. 80-83.

51. "Résurrection de Gerbéviller-la-Martyre », La Semaine religieuse du diocèse de Nancy et de Toul, 7 juillet 1923, p. 420.

52. Ibid.

53. "Consécration des autels majeurs à Hussigny et à Longwy-Haut », La Semaine religieuse du diocèse de Nancy et de Toul, 14 août 1926, p. 521-524. 
54. «Bénédiction de l'église de Prény ", La Semaine religieuse du diocèse de Nancy et de Toul, 22 novembre 1924, p. 736-737.

55. "Bénédiction de l'église de Pannes », La Semaine religieuse du diocèse de Nancy et de Toul, 13 octobre 1923, p. 640.

56. Ibid.

57. Lucien Thouvenin, « Pourquoi la Coopérative des églises fait un emprunt ", La Semaine religieuse du diocèse de Nancy et de Toul, 16 juillet 1921, p. 394-396 et Paul Fiel, L'œuvre de la Coopérative de reconstruction des églises du diocèse de Nancy et de Toul, Nancy, 1927, 40 p., p. 13.

58. «Monseigneur l'évêque à Bionville ", La Semaine religieuse du diocèse de Nancy et de Toul, 30 septembre 1922, p. 556.

59. L'Église de Nomeny. La consécration de la nouvelle église, Nancy, Ancienne imprimerie Vagner, Nancy, 1928, 32 p., p. 6.

60. "Bénédiction de l'église de Pannes », La Semaine religieuse du diocèse de Nancy et de Toul, 13 octobre 1923, p. 640.

61. Diocèse de Nancy et de Toul, Exposition de l'œuvre des églises dévastées, 13-15 avril 1919, Nancy, Crépin-Leblond, 1919, 24 p., p., p. 4.

62. Malgré l'évolution des méthodes de guerre, le rôle militaire des clochers apparaissait encore, pendant la deuxième Guerre mondiale, comme l'explication la plus plausible des destructions. Le maire d'Emberménil affirmait ainsi, en 1944: «Je suppose que les Allemands ont fait sauter l'église parce qu'ils craignaient que les Américains s'en servent comme observatoire. Je ne vois pas d'autres motifs ", cf. procès-verbal du 11 octobre 1944, Arch. dép. Meurthe-et-Moselle $14 \mathrm{~W}$ 208.

63. Une Victoire oubliée. La bataille du Grand-Couronné, août-septembre 1914, catalogue de l'exposition du musée historique lorrain, 26 août-23 octobre 1914, 24 p.

64. Pour faire face aux conséquences patrimoniales de la séparation de 1905, l'État a été conduit, entre 1906 et 1913, à classer près de 2000 églises parmi les monuments historiques, cf. Paul Léon, Les Monuments historiques. Conservation. Restauration, Paris, Henri Laurens, 1917, IV-380 p., p. 79. Cf. aussi Arlette Auduc, Quand les monuments construisaient la nation. Le service des monuments historiques de 1830 à 1940, Paris, Comité d'histoire du ministère de la Culture, 2008, 640 p., p. 307 et suivantes.

\section{RÉSUMÉS}

Pendant toute la durée de la Première Guerre mondiale, l'évêque de Nancy accusa les troupes allemandes de s'acharner sur les églises de son diocèse, dans le but de "détruire l'Église catholique ». Les catholiques allemands réfutèrent cette accusation. Les photographes français s'efforcèrent, pour leur part, de publier des preuves visuelles du «sacrilège ", dans la presse ou sous forme de cartes postales. Les dossiers de dommages de guerre prouvent que les armées allemandes ont utilisé les églises pour des buts militaires. Mais, d'après ces dossiers, les Français ont aussi instrumentalisé les églises. Français et Allemands détruisirent en fait les églises, au mépris des engagements qu'ils avaient pris lors de la quatrième conférence de La Haye (1907) en vue de protéger les lieux de culte en cas de guerre. Des statistiques établies par la préfecture de 
Meurthe-et-Moselle indiquèrent dès 1919 que les églises du département n'avaient pas été particulièrement visées par les Allemands. La destruction des églises demeura cependant un enjeu symbolique important, au moins jusqu'à la fin des années 1930.

During all the First World War, the bishop of Nancy accused the German troops of being incensed against churches with the aim of « destroying the Roman Catholic Church » in his diocese. The German Catholics refuted this charge. The French photographers tried, for their part, to publish visual proofs of the "sacrilege ", in the press or in the form of postcards. The files of war damage prove that the German armies used churches for military purposes. But, according to these files, the French did the same. French and Germans destroyed in fact churches, in defiance of the commitments which they had taken during the fourth conference of The Hague (1907) to protect churches in case of war. In 1919, statistics established by the prefecture of Meurthe-et-Moselle indicate that the churches of the department had not been particularly aimed by the Germans. The destruction of churches remained however an important symbolic stake, at least till the end of 1930 s.

Im gesamten Verlauf des ersten Weltkrieges warf der Bischof von Nancy den deutschen Soldaten immer wieder vor, die Kirchen seiner Diözese anzugreifen und dabei die katholische Kirche vernichten zu wollen. Diese Anklage wurde aber von den deutschen Katholiken zurückgewiesen. Die französischen Fotografen bemühten sich ihrerseits, in Zeitschriften oder mittels Ansichtskarten augenscheinliche Proben von diesem Sakrileg zu veröffentlichen. Je nach den Unterlagen der Kriegsschäden wurde zwar festgestellt, dass die deutschen Streitkräfte Kirchen als militärische Ziele genommen haben, aber ebenso die Franzosen diese für ihre eigenen Zwecke gebraucht haben. In der Tat haben die Deutschen, ebenso wie die Franzosen Kirchen zerstört. Beiderseits wurden also die Verpflichtungen der vierten Konferenz von Den Haag (1907) übertreten, nach denen Kultusgebäude im Kriegsfall zu schützen waren. Schon 1919 zeigten aber Statistiken der Préfecture, dass die Deutschen die Kirchen des Départements Meurthe-et-Moselle nicht als ausgesprochenes Ziel genommen haben. Immerhin behielten die Kirchenzerstörungen wenigstens bis in die dreißiger Jahre eine besondere symbolische Bedeutung.

\section{INDEX}

Index chronologique : XXe siècle

Mots-clés : église

Keywords : church

Schlüsselwörter : Kirche

\section{AUTEUR}

\section{NICOLAS PADIOU}

Nicolas Padiou est né en 1976. Il a passé, en 1999, une maîtrise d'histoire de l'art à l'université de Nancy II (Les Enjeux d'un grand projet néogothique : la reconstruction de l'église Saint-Epvre de Nancy, 1863-1871). Il a ensuite soutenu, en 2001, un DEA à l'Éphé sous la direction de Jean-Michel Leniaud (L'Immeuble et la construction dans l'Est, une revue d'architecture lorraine, Nancy, 1887-1914). Il a soutenu une thèse en cotutelle (Éphé-université technique de Dresde), sur La Reconstruction des églises de Meurthe-et-Moselle après la Première Guerre mondiale (1918-1933). Il a récemment publié un article sur « Quelques thèmes religieux dans les caricatures anti-allemandes pendant la Première 
Guerre mondiale », dans Ridiculosa $\mathrm{n}^{\circ} 15,2008$, « Caricature et religion(s) ». Adresse électronique : nicolas.padiou@freenet.de 